\title{
Ion Drift Measured by MU Radar and Its Comparison with Geomagnetic Field Variation
}

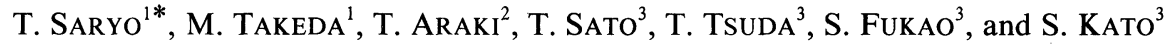 \\ ${ }^{1}$ Department of Geophysics, Kyoto University, Kyoto 606, Japan \\ ${ }^{2}$ Data Analysis Center for Geomagnetism and Space Magnetism, Kyoto University, Kyoto 606, Japan \\ ${ }^{3}$ Radio Atmospheric Science Center, Kyoto University, Uji 611, Japan
}

(Received August 10, 1988; Revised March 31, 1989)

\begin{abstract}
By using MU radar at Shigaraki, Japan, ion drift and the electron density profile in the $F$ region were observed during two periods, September 17-18 and October 7-8, 1986. Between $23 \mathrm{~h}$ LT and $24 \mathrm{~h}$ LT on September 17, a clear difference was found between the electron density profiles observed by the eastward and westward beams, which may be caused by a wave propagated from east to west. A clear negative correlation between the perpendicular northward $\left(V_{\perp}\right)$ and parallel $\left(V_{/ I}\right)$ component of the velocity, which is caused by the $F$ region dynamo action, was found as observed at Arecibo. The daily variation pattern of $V_{\perp}$ was similar to that observed at Arecibo, especially in the daytime, but that of the eastward drift was different. Geomagnetic field variations were estimated by using a drift velocity and conductivities deduced from the IRI 79 model (IRI 79, 1981) compared to observations at Miyazu, approximately $110 \mathrm{~km}$ northwest of the radar site. Discordance between the estimated and observed field variations was concluded to be caused by ionospheric winds, which contribute to the generation of the geomagnetic $S q$ field through the induced electric field.
\end{abstract}

\section{Introduction}

Incoherent scatter (IS) radar is a powerful tool for studying ionospheric physics. Using this radar we can observe altitude profiles of various parameters: electron density, temperature, composition, electric field, neutral winds, and so on. In the middle- and low-latitude regions, many measurements have been made by radars at Jicamarca, Arecibo, Millstone Hill, Saint Santin and Malvern. HARPER (1977) and MAZAUDIER (1982) calculated geomagnetic field variation from the drift observation and found a fairly good accordance with the observed geomagnetic field variation. RICHMOND et al. (1980) used the former four observatories to produce a model of the electric field in the middle- and low-latitude regions, and obtained the seasonal and universal time (UT) dependence of the electrostatic potential. However, their results for the UT variation were based on observations made in the American and European zones only, because of the lack of observations in other

*Now at NEC Corporation. 
regions. OLIVER et al. (1988) reported the first ion-drift measurements made by MU radar at Shigaraki $\left(34.85^{\circ} \mathrm{N}, 136.10^{\circ} \mathrm{E}\right)$, Japan, from October 1986 to January 1987. Their study indicates that MU radar can contribute to the study of ionospheric plasma drifts.

In this paper we first present results of the observations of the ion-drift and electron density in the ionosphere made by MU radar in two periods in September and October 1986. Second, geomagnetic field variation is estimated from the drift and electron density data. Last, we compare the estimated variation with the observed geomagnetic field at Miyazu $\left(35.32^{\circ} \mathrm{N}, 135.15^{\circ} \mathrm{E}\right)$, approximately $110 \mathrm{~km}$ northwest of the radar site.

\section{Measurement}

The MU radar at Shigaraki is a $46.5 \mathrm{MHz}$ pulse-modulated monostatic Doppler radar with an active phased-array system. The antenna is a circular array of 475 crossed Yagi elements which are connected to a separate low-power transmitreceive module. The radiation power is $1 \mathrm{MW}$, with a maximum average power of $50 \mathrm{~kW}$. Details of the radar system were discussed by FUKAO et al. (1985a, b) and techniques of the measurements were presented by SATO et al. (1989). We observed the ionosphere in the following two periods: one from $10 \mathrm{~h} \mathrm{LT}$ on September 17 to $07 \mathrm{~h} \mathrm{LT}$ on September 18 (from $01 \mathrm{~h}$ UT to $22 \mathrm{~h}$ UT on September 17), 1986 and the other from $00 \mathrm{~h} \mathrm{LT}$ on October 7 to $03 \mathrm{~h} \mathrm{LT}$ on October 8 (from $15 \mathrm{~h}$ UT on October 6 to $18 \mathrm{~h}$ UT on October 7), 1986. In both periods measurements were made by the following two schemes:

1) Measurements of electron density (power mode)

A simple 448 microsecond pulse modulated by a 7-bit Barker code was used. The altitude range is from 150 to $450 \mathrm{~km}$ and the height resolution is $9.6 \mathrm{~km}$ along the beam direction.

2) Measurements of ion drift (double pulse mode)

Double pulses of 256 microsecond width and 552 microsecond separation were used to measure the Doppler velocity. Though the height resolution determined by the pulse is $38.4 \mathrm{~km}$, we calculate and discuss the velocity averaged over a height range from $230 \mathrm{~km}$ to $300 \mathrm{~km}$, on the assumption that the velocity was constant in the $F$ region.

The radar was operated by scheme 1 for the first $15 \mathrm{~min}$ of every hour and by scheme 2 for the remaining $45 \mathrm{~min}$. The beam of the radar must be pointed in at least three directions in order to measure the drift velocity vector. In the present measurements we used four beams tilted by $20^{\circ}$ from the zenith, with the azimuthal angles of $85^{\circ}, 175^{\circ}, 265^{\circ}$ and $355^{\circ}$, measured clockwise from the geographical north. Since the geomagnetic declination angle at Shigaraki is $6^{\circ}$ west and the beamwidth was $3.6^{\circ}$, this means that the beam was directed in the meridional plane including the geomagnetic field line and in the plane perpendicular to the meridional plane.

In the present observation we estimated the absolute value of the electron 
density from the height profile of the echo strength by calibrating the maximum electron density obtained from observation by an ionosonde at the radar site. Details of the method are shown by OLIVER et al. (1988). We mainly treat the electron density profile averaged over the four beams, but difference among the results obtained by the four beams is also discussed in Section 3.

The drift velocity along the line-of-sight $\left(V_{\mathrm{d}}\right)$ is calculated from the complex auto-correlation function $(A C F)$. The $A C F$ analysis method used here was described in FUKAO et al. (1979). Using the $A C F, V_{\mathrm{d}}$ is given as

$$
V_{\mathrm{d}}=\frac{\lambda}{4 \pi \tau} \frac{\operatorname{Re}(A C F)}{\operatorname{Im}(A C F)},
$$

where $\lambda$ is the wavelength of the transmitted wave, Re and Im are real and imaginary parts of $A C F$ and $\tau$ is the time lag. Positive $V_{\mathrm{d}}$ means that the velocity is directed toward the radar. In the present analysis, we calculated the velocity vector by varying the azimuthal direction with a fixed zenith angle (the VAD method). Since the azimuthal angles of the two neighboring beams are at right angles, we can obtain the velocity vector as follows:

$$
\begin{aligned}
& V_{\mathrm{S}}=\left(V_{1}-V_{3}\right) /(2 \sin Z e), \\
& V_{\mathrm{E}}=\left(V_{4}-V_{2}\right) /(2 \sin Z e), \\
& V_{\mathrm{U}}=-\left(V_{1}+V_{2}+V_{3}+V_{4}\right) /(4 \cos Z e),
\end{aligned}
$$

where $V_{\mathrm{S}}, V_{\mathrm{E}}$ and $V_{\mathrm{U}}$ are the southward, eastward and upward components of the vector of ion drift, respectively, $V_{1}, V_{2}, V_{3}$ and $V_{4}$ are $V_{\mathrm{d}}$ observed by the beams of $355^{\circ}, 85^{\circ}, 175^{\circ}$ and $265^{\circ}$ azimuthal angles, respectively and $Z e$ is the zenith angle $\left(20^{\circ}\right)$. We can obtain the component of the drift velocity parallel ( $V_{/ /}$, upward positive) and perpendicular ( $V_{\perp}$, northward positive) to the geomagnetic field as follows:

$$
\begin{aligned}
& V_{/ /}=V_{\mathrm{S}} \cos I+V_{\mathrm{U}} \sin I, \\
& V_{\perp}=-V_{\mathrm{S}} \sin I+V_{\mathrm{U}} \cos I,
\end{aligned}
$$

where $I$ is the dip angle at Shigaraki $\left(49^{\circ}\right)$. The electric field is calculated by assuming that the perpendicular component of the velocity is equal to the $\boldsymbol{E} \times \boldsymbol{B} \mathrm{drift}$ velocity.

\section{Results in September}

September 17 was a geomagnetically slightly disturbed day; $\Sigma K p$ was 22 and Dst was almost constant all day with a mean value of $-32 \mathrm{nT}$. Figure 1 gives the altitude profile of the electron density. It should be noted that the electron density 


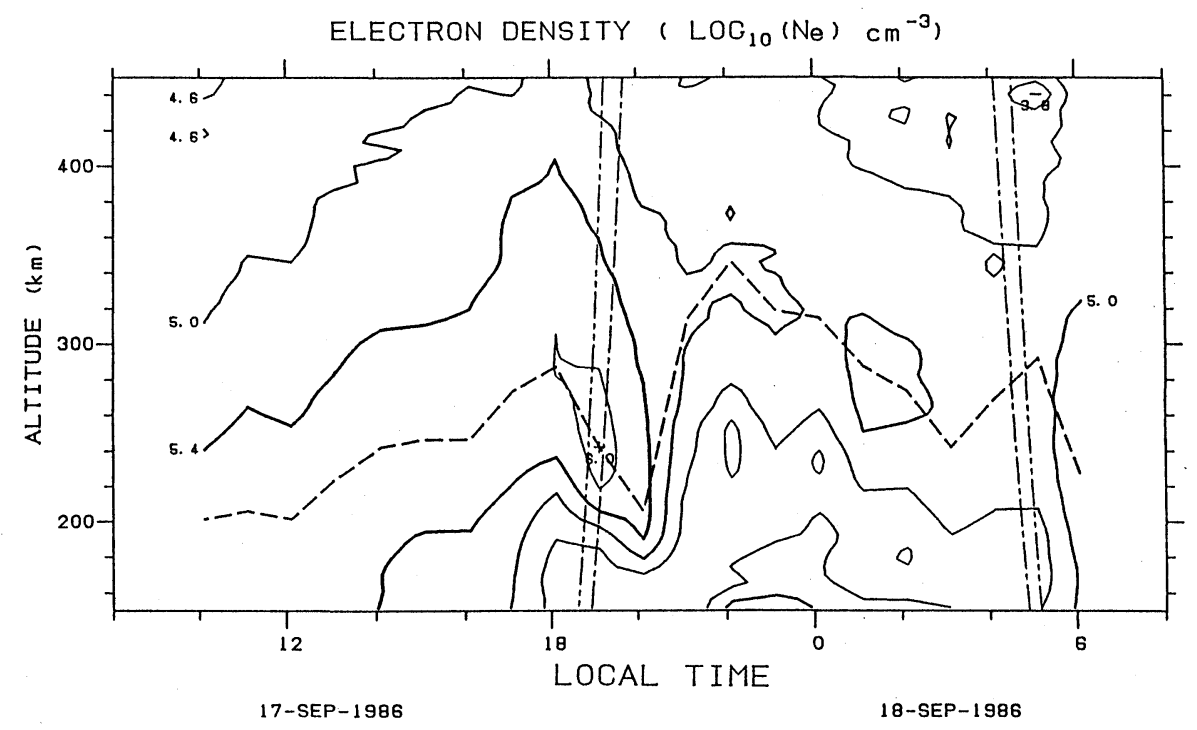

Fig. 1. Time variation of electron density profile from $10 \mathrm{~h} \mathrm{LT}$ on September 17 to $07 \mathrm{~h} \mathrm{LT}$ on September 18, 1986. Contours are drawn at every 0.4 in $\log _{10}\left(\mathrm{Ne}\left(\mathrm{cm}^{-3}\right)\right)$. Dashed line represents the altitude of the $F 2$ peak, dot-dashed line the sunrise or sunset time, and dot-dot-dashed line the time of the conjugate point.

below $200 \mathrm{~km}$ altitude is not so reliable because of contamination by meteor echoes (SATO et al., 1989). The most remarkable feature is that the peak altitude of the electron density decreases by about $80 \mathrm{~km}$ during a two hour period centered at sunset. One hour after sunset, the peak altitude begins to increase. At first the maximum electron density increases with the decrease of the peak altitude, and then decreases after sunset.

Figures 2(a), (b), (c) and (d) give the daily variation of $V_{\mathrm{U}}, V_{/ /}, V_{\perp}$ and $V_{\mathrm{E}}$, respectively. Error bars show the estimated error due to the background noise. The absolute value of $V_{\mathrm{U}}$ is affected by the offset of the radar system. Here the offset value along the line-of-sight is assumed to be $-33 \mathrm{~m} / \mathrm{s}$ and constant all day. If we take this value for the offset, $V_{\mathrm{U}}$ in Fig. 2 changes its sign from downward to upward according to the descent and ascent of the $F 2$ peak near sunset. The effect of this offset is canceled out when the horizontal velocities are derived, because only the differences between the observed drift velocities are necessary to estimate the horizontal velocities shown in Eqs. (2) to (3), while the summation of the observed velocities is used to estimate the vertical velocity (Eq. (4)). Corresponding to the above-mentioned variation of the peak altitude, $V_{\perp}$ decreases between $18 \mathrm{~h}$ and $20 \mathrm{~h}$ LT and increases after $20 \mathrm{~h} \mathrm{LT}$. $V_{/ /}$does not show such a clear variation between 18 $\mathrm{h}$ and $20 \mathrm{~h} \mathrm{LT}$. This suggests that the variation of $V_{\perp}$ caused the variation in the vertical distribution and the peak density from $18 \mathrm{~h}$ to $20 \mathrm{~h} \mathrm{LT}$. Except for the period from $18 \mathrm{~h}$ to $22 \mathrm{~h} \mathrm{LT}$, negative correlation between $V_{/ /}$and $V_{\perp}$ is seen. This is 


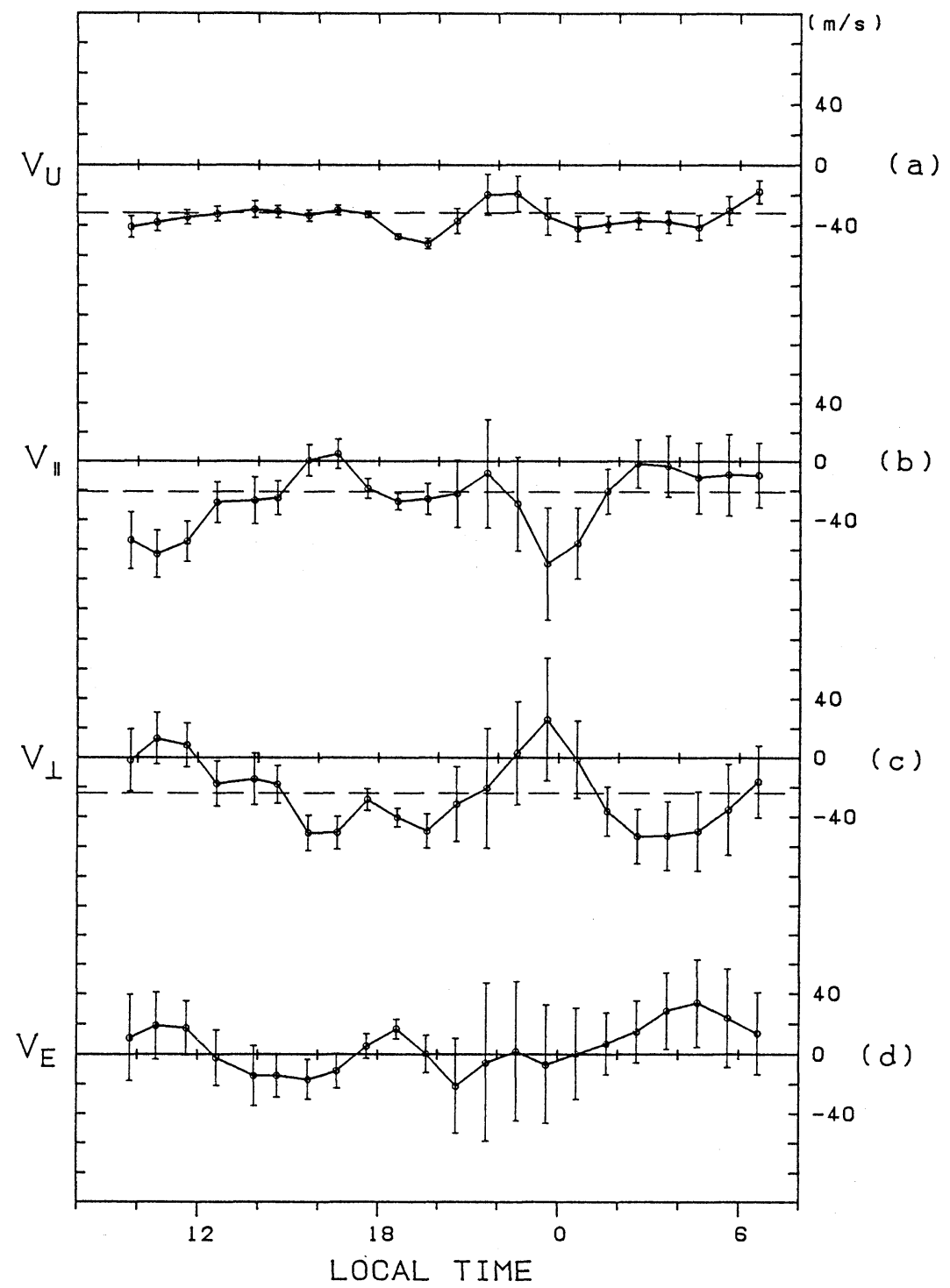

$17-S E P-1986$

$18-S E P-1986$

Fig. 2. Vertical upward $\left(V_{\mathrm{U}}\right)(\mathrm{a})$, parallel upward $\left(V_{/ /}\right)(\mathrm{b})$, perpendicular northward $\left(V_{\perp}\right)$ (c) and eastward $\left(V_{\mathrm{E}}\right)(\mathrm{d})$ components of the ion drift velocity from $10 \mathrm{~h} \mathrm{LT}$ on September 17 to $07 \mathrm{~h} \mathrm{LT}$ on September 18, 1986. Horizontal dashed lines show the estimated zero levels, assuming that the offset value along the line of sight is $-33 \mathrm{~m} / \mathrm{s}$. 
consistent with the observation at Arecibo by BEHNKE and HARPER (1973), and attributed to the $F$ region dynamo by OLIVER et al. (1988).

In Fig. 1, there is a peak in the electron density at about $19 \mathrm{~h} \mathrm{LT}$ on September 17. This peak occurs during a downward drift beginning at $18 \mathrm{~h} \mathrm{LT}$. At first glance it is not reasonable that the electron density is enhanced during the downward drift, because this drift pushes plasma down to the high loss rate region. However, Figure 2 shows that $V_{\mathrm{E}}$ is eastward before $19 \mathrm{~h} \mathrm{LT}$ and then turns westward. This means that plasma converges in the east-west direction around $19 \mathrm{~h} \mathrm{LT}$, if we regard the time variation as a spatial variation. It is possible that this convergence causes the peak of the electron density.

Unfortunately, it is difficult to accurately measure the electron density in the $E$ region as mentioned above, because the signals from the $E$ region are often contaminated by meteor echoes. Thus we have calculated the ionospheric conductivities using the IRI 79 model, foF 2 obtained by ionosonde at the radar site and $h m F 2$ by radar observation in the power mode. Since no measurement was made of the neutral winds, because of limitations in the capability of the MU radar, the effects of the neutral winds on the ionospheric currents were ignored in estimation of the currents for the present. Geomagnetic field variations by the currents are estimated on the assumption that the currents are horizontally uniform and the intensity of the currents induced in the Earth is half of that of the ionospheric currents. The calculated geomagnetic field variation is then compared with the horizontal geomagnetic field variation observed at Miyazu.

Figure 3 shows the height-integrated Pedersen (solid lines) and Hall (dashed lines) conductivities on September 17. Figure 4 gives the geomagnetic $H$ (a) and $D$ (b) components at Miyazu. The errors in the observed geomagnetic field variations

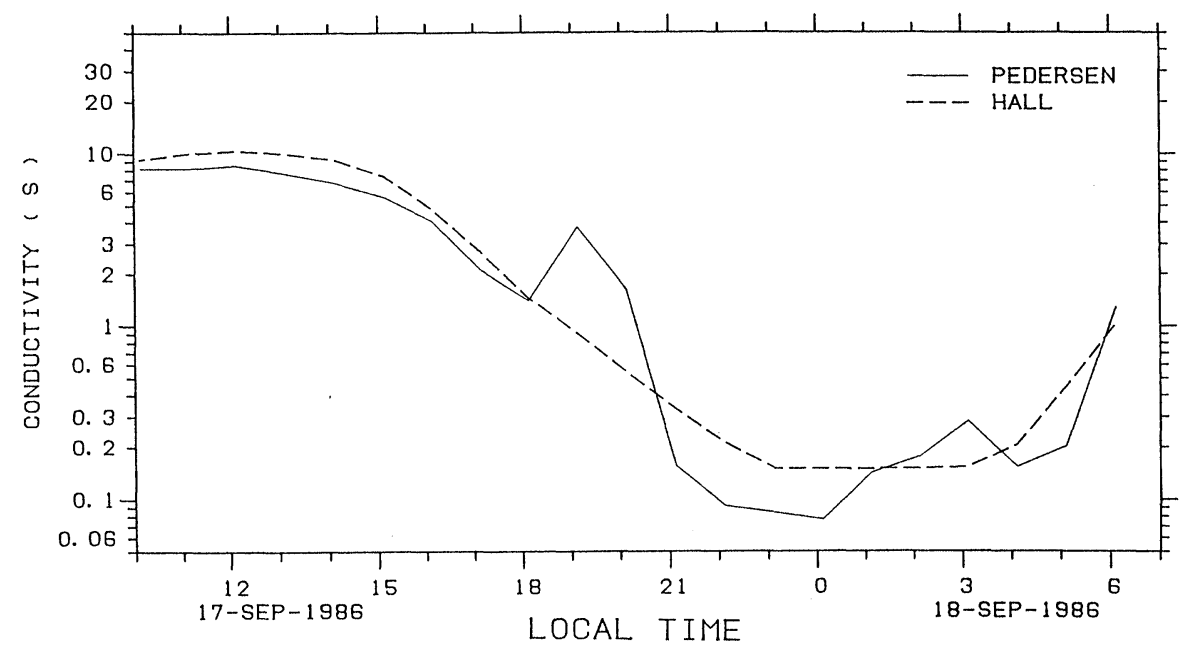

Fig. 3. Height-integrated Pedersen (solid line) and Hall (dashed line) conductivities from $10 \mathrm{~h} \mathrm{LT}$ on September 17 to $07 \mathrm{~h}$ LT on September 18, 1986. 

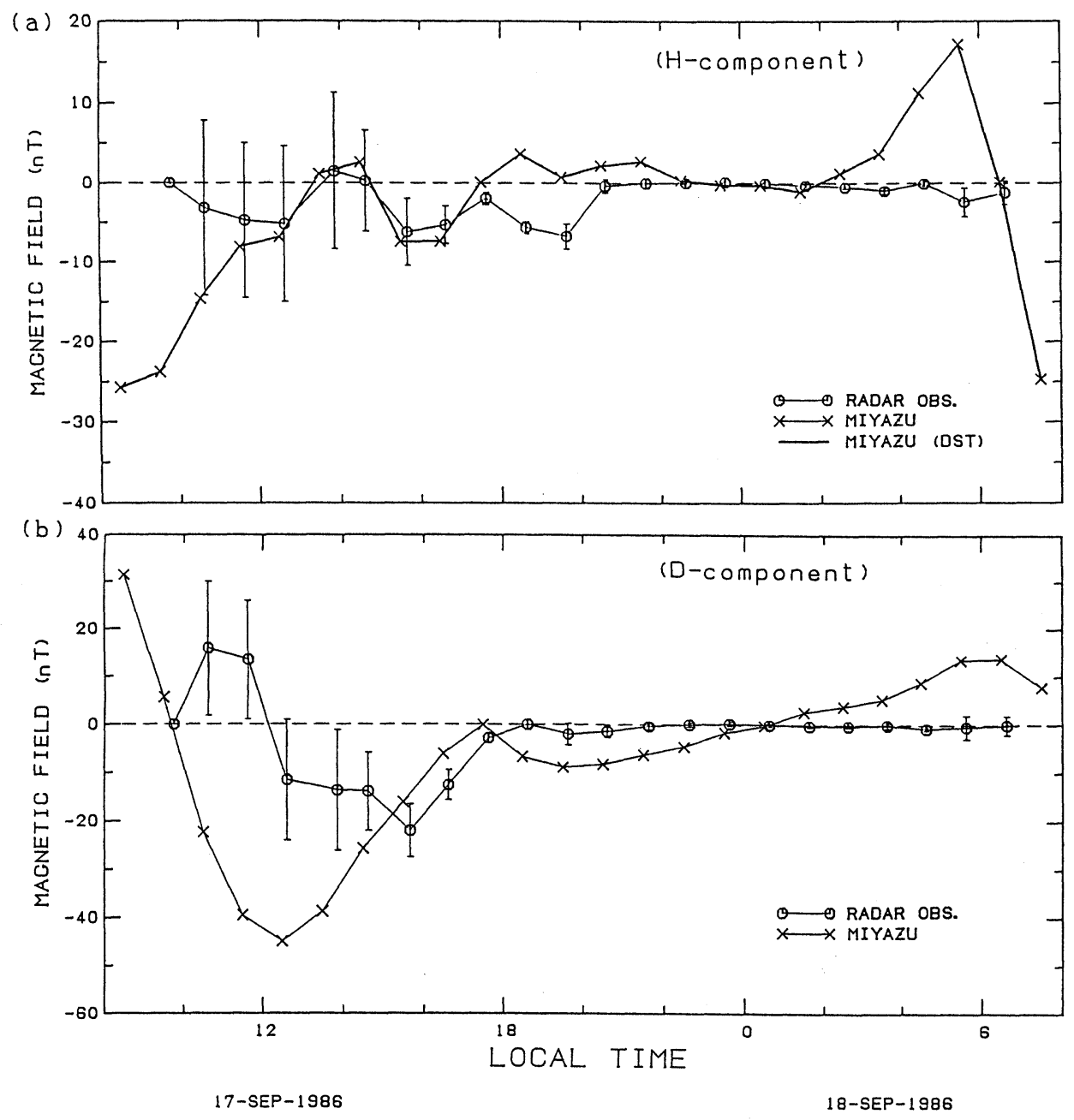

Fig. 4. (a) Calculated $H$-component of the geomagnetic field from radar observation (circles), observed $\boldsymbol{H}$-component at Miyazu (crosses and thin line), and observed $\boldsymbol{H}$-component at Miyazu corrected by the $D s t$ index (thick line) from $10 \mathrm{~h} \mathrm{LT}$ on September 17 to $07 \mathrm{~h}$ LT on September 18, 1986. Since in this period Dst did not vary so much, the thin and thick lines are almost identical. (b) Calculated $D$-component of the geomagnetic field from radar observation (circles and thin line), observed $H$-component at Miyazu (crosses and thick line) from $10 \mathrm{~h} \mathrm{LT}$ on September 17 to $07 \mathrm{~h} \mathrm{LT}$ on September 18, 1986.

are confirmed to be less than $5 \mathrm{nT}$ by comparison with the total geomagnetic field variation observed by proton magnetometer. Circles represent the calculated magnetic field and crosses the deviation of the observed geomagnetic field from the mean value around local midnight. The $D s t$ correction to the $H$ component was 

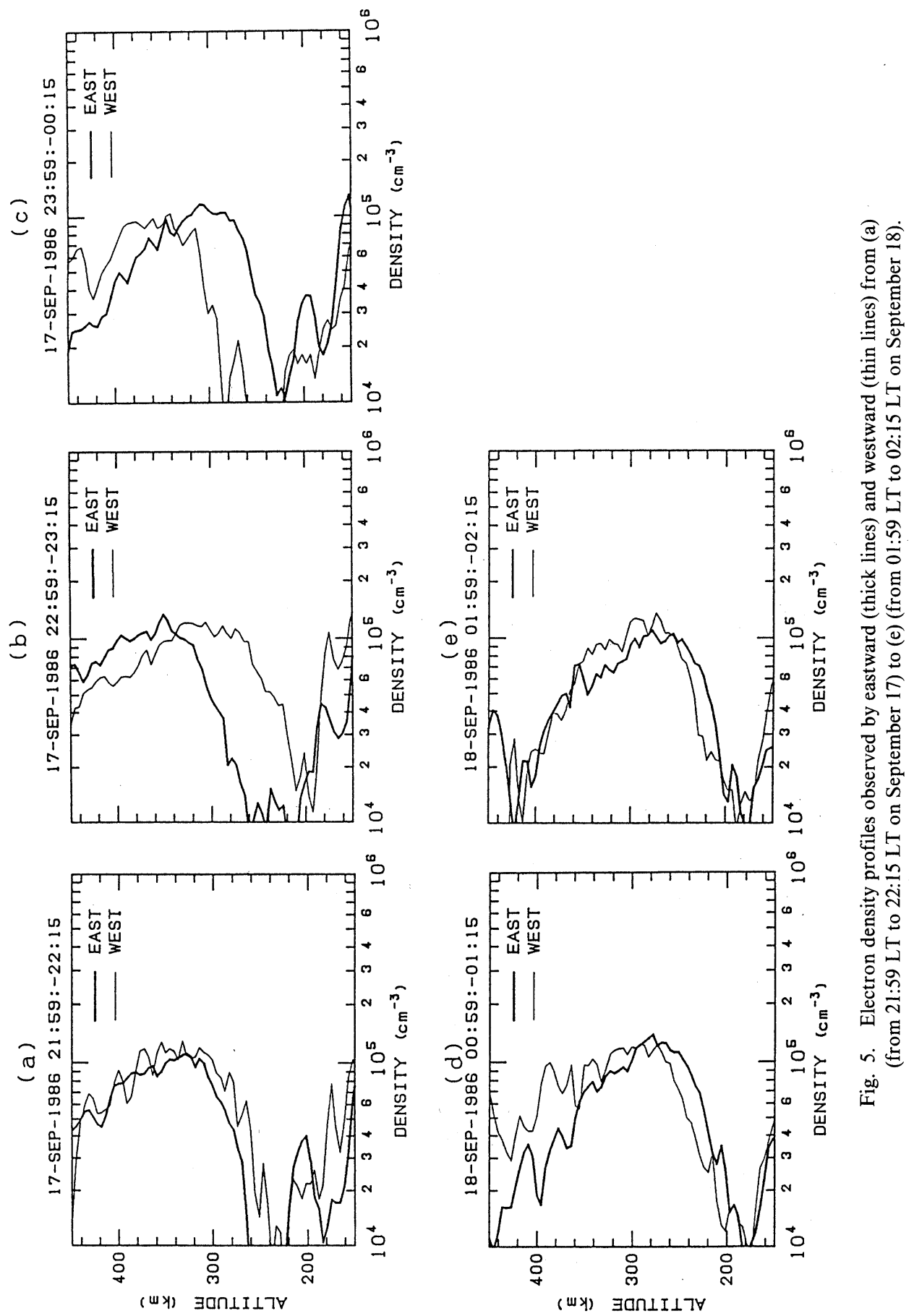
made by the method presented by TAKEDA (1984) and the resultant values are shown by solid lines, although on September 17 the $D s t$ did not vary so much and therefore the Dst correction does not make so much difference.

The variation in the $H$ component from $13 \mathrm{~h} \mathrm{LT}$ to $18 \mathrm{~h} \mathrm{LT}$ on September 17 is well reproduced by the calculation, but before $12 \mathrm{~h} \mathrm{LT}$ on September 17 and after 02 $\mathrm{h}$ LT on September 18 the accordance is not so good. There is also a clear discordance between the observed and estimated $H$ components from $18 \mathrm{~h}$ LT to 20 $\mathrm{h}$ LT. This may be caused by wrong estimation of the conductivity, because the conductivity derived from the model ionosphere does not include the effect of the variation in electron density observed in this period. As for the $D$ component, the correspondence is not good before $15 \mathrm{~h} \mathrm{LT}$ on September 17 and after $03 \mathrm{~h} \mathrm{LT}$ on September 18. The disagreement in the daytime seems to be caused by neutral winds. On the other hand, the discordance in the morning on September 18 appears to be caused by currents outside of the ionosphere, because the ionospheric conductivity is low in this period and the ionosphere seems unable to flow enough currents.

On this night, an interesting behavior is found in the electron density profiles measured by the eastward and westward beams. In the period before $19 \mathrm{~h} \mathrm{LT}$ there is no significant difference between those profiles. However, a clear difference in the profile is found between $22 \mathrm{~h} \mathrm{LT}$ on September 17 to $02 \mathrm{~h} \mathrm{LT}$ on September 18. Figure 5 shows the profile measured by the eastward (thick lines) and westward (thin lines) beams sequentially from (a) (from 21:59 LT to 22:15 LT on September 17) to (e) (from 01:59 LT to 02:15 LT on September 18). In Fig. 5(a) the profiles by the two beams are almost identical. However, in Fig. 5(b) (from 22:59 LT to 23:15 LT on September 17) the profile by the eastward beam shifts upward compared with that by the westward beam. The electron density profiles measured by the northward and southward beams are almost the same as that measured by the westward beam. After one hour (Fig. 5(c), from 23:59 LT on September 17 to 00:15 LT on September 18) this relation is reversed. In this period the northward profile was similar to the eastward profile, but the southward profile was between the westward and eastward profiles. Around $01 \mathrm{~h} \mathrm{LT}$ on September 18, the profiles by the eastward and westward beams again agree with each other (Fig. 5(d), from 00:59 LT to 01:15 LT on September 18). This suggests that the enhancement of $V_{\perp}$ at about midnight appearing in Fig. 2(c) occurred earlier in the eastward region than in the westward region, and caused the earlier upward shift of the electron density profile.

\section{Results in October}

October 7 and 8 were geomagnetically quiet days; maximum $K p$ was 2 . Figure 6 gives the electron density profile. Figures $7(\mathrm{a}),(\mathrm{b})$, (c) and (d) show $V_{\mathrm{U}}, V_{/ /}, V_{\perp}$ and $V_{\mathrm{E}}$, respectively. From $12 \mathrm{~h}$ to $15 \mathrm{~h} \mathrm{LT}$ on October 7, the $V_{\mathrm{U}}$ had strong negative (downward) values, but there was not as clear a descent of the $F 2$ peak as on September 7. From $02 \mathrm{~h} \mathrm{LT}$ on October 8, system noise increased and reduced the reliability of the obtained data. $V_{\perp}$ shows good accordance with that observed at 


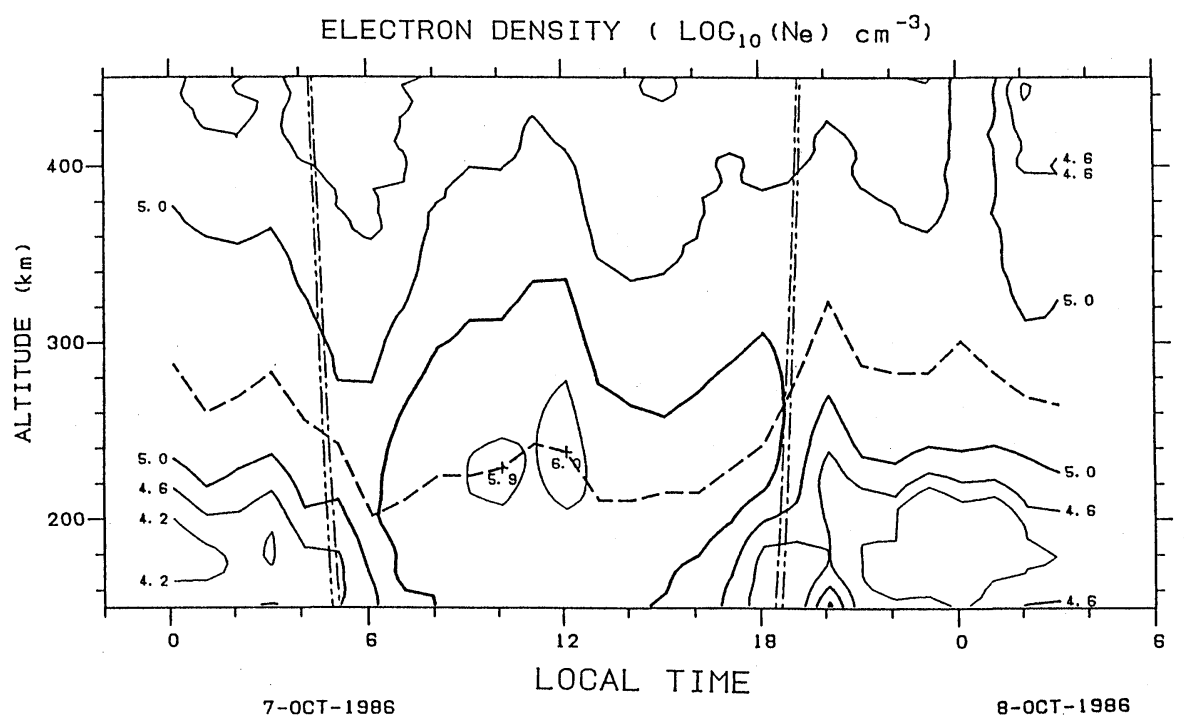

Fig. 6. Same as in Fig. 1, but from $00 \mathrm{~h} \mathrm{LT}$ on October 7 to $03 \mathrm{~h}$ LT on October 8, 1986.

Arecibo (GAUGULY et al., 1987) and the simulation by TAKEDA and YAMADA (1987), especially in the daytime. Examining in more detail, one finds that there is a small difference of the time of the maximum $V_{\perp}$ between our result $(09 \mathrm{~h} \mathrm{LT})$ at Shigaraki and that (11 h LT) at Arecibo under quiet equinoctial condition. Since both observations were made under nearly solar minimum conditions and in geomagnetically quiet period, this may result from the UT variation of the ionospheric electric field. In fact, the simulation by TAKEDA and YAMADA (1987) showed that the eastward electric field, which corresponds to positive $V_{\perp}$, maximizes at 09:30 LT, which is between the two observed times at Shigaraki and Arecibo. This is natural if we remember that the shift of the geomagnetic equator is northward and southward in the Japanese and American zones, respectively, and if this shifts it may cause the difference of the time of the maximum eastward electric field. On the other hand, the variation of $V_{\mathrm{E}}$ in Fig. 8 does not agree with that at Arecibo very well. However, the $V_{\mathrm{E}}$ at Arecibo itself does not show such good agreement with $V_{\mathrm{E}}$ obtained by the simulation. This suggests that $V_{\mathrm{E}}$ is more sensitive to the local effect than $V_{\perp}$. At Arecibo the diurnal variation is dominant in both $V_{\mathrm{E}}$ and $V_{\perp}$, but in those at Shigaraki, the semidiurnal variation is conspicuous in both periods. This agrees with the results of OLIVER et al. (1988).

Figure 8 shows the height-integrated Pedersen (solid lines) and Hall (dashed lines) conductivities on October 7. Figure 9 gives the geomagnetic $H$ (a) and $D$ (b) components at Miyazu. The Dst correction is effective because $D s t$ varies by $10 \mathrm{nT}$ in the observation period. In general, the correspondence between the observed and estimated variations in the geomagnetic field is good, except for the $H$ component 


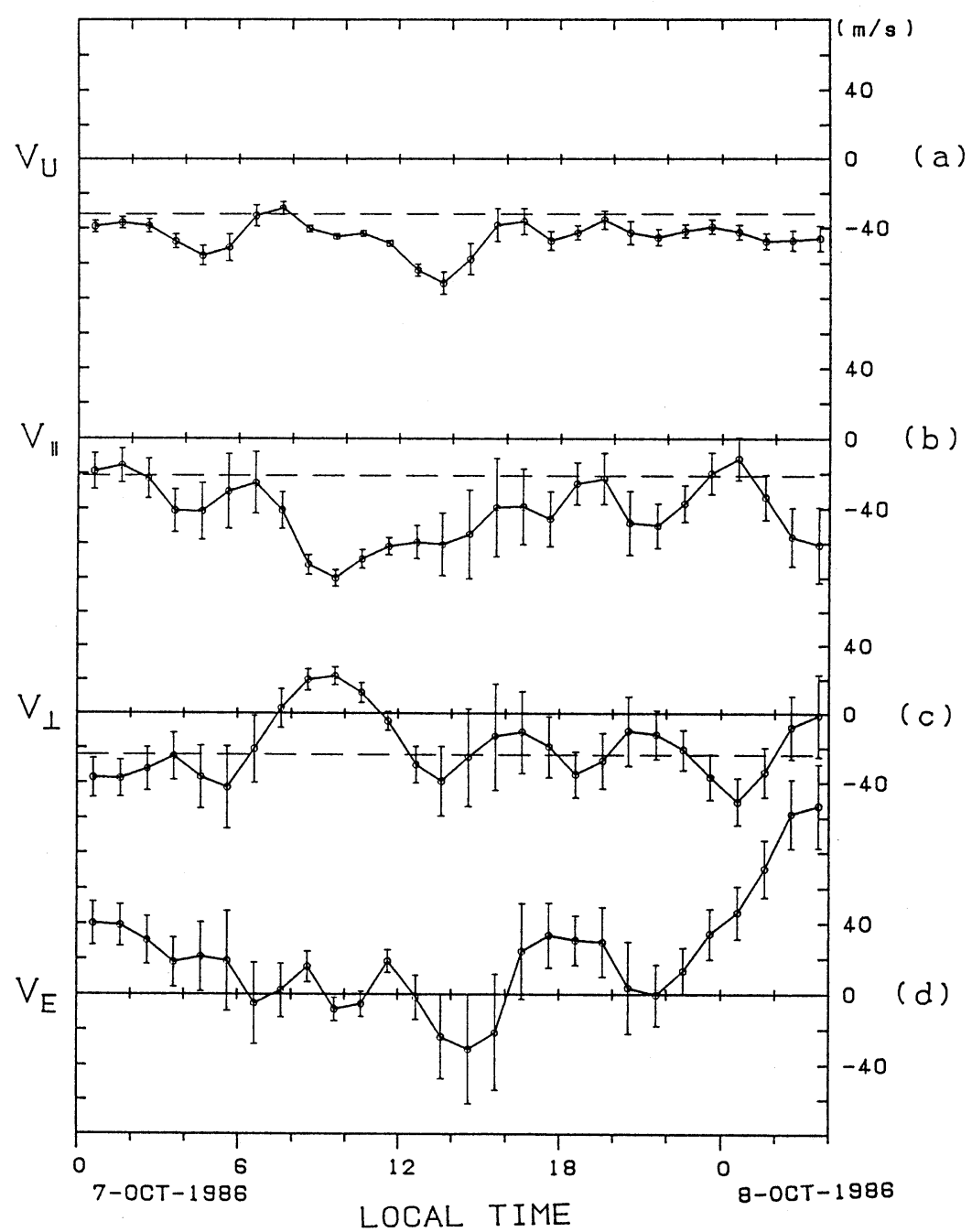

Fig. 7. Same as in Fig. 2, but from $00 \mathrm{~h} \mathrm{LT}$ on October 7 to $03 \mathrm{~h} \mathrm{LT}$ on October 8, 1986.

from $08 \mathrm{~h} \mathrm{LT}$ to $12 \mathrm{~h} \mathrm{LT}$ on October 7, which also seems to be caused by the neutral winds. Since the period from October 7 to 8 was geomagnetically quiet, the discordance between the calculated and observed geomagnetic fields seems to be caused by the electric field induced by the neutral winds, even if the effect of $D s t$ was removed. We have calculated the wind velocity assuming that the discordance is solely due to the neutral wind. The mean wind velocity $(U)$ which can be estimated is the mean wind velocity weighted by the conductivity as follows: 


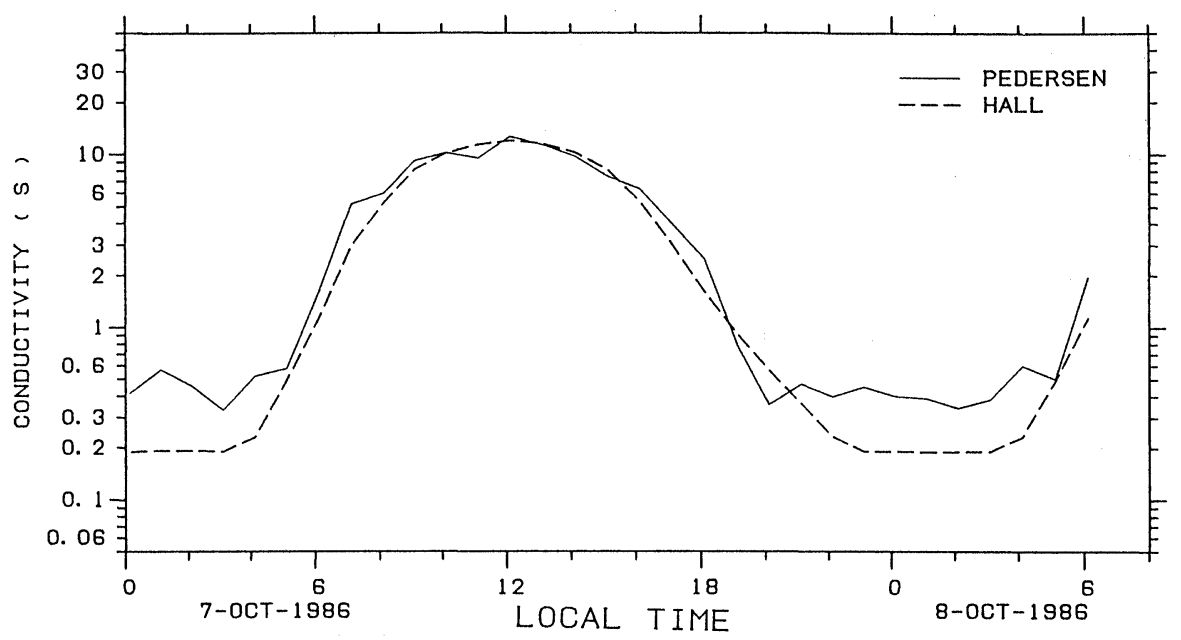

Fig. 8. Same as in Fig. 3, but from $00 \mathrm{~h} \mathrm{LT}$ on October 7 to $03 \mathrm{~h} \mathrm{LT}$ on October 8, 1986.

$$
U=\Sigma^{-1} / B \int \sigma(u \times B) \mathrm{d} z,
$$

where $\sigma$ is the conductivity tensor, $\Sigma$ is the height integration of $\sigma, u$ is the real neutral winds, and $B$ is the magnetic flux density. It should be noted that the mean wind $U$ obtained here is principally the wind averaged in the $E$ region where the electric conductivity is large. Figure 10 shows the result. The obtained wind in the nighttime is not shown here, because a small error in either the observed or calculated geomagnetic field may introduce a large error in winds through low conductivity in the nighttime, and the wind is not reliable. The wind direction is westward in the morning and eastward in the afternoon. This agrees with the direction of the winds generating the geomagnetic $S q$ field suggested by FUKUSHIMA $(1968,1979)$ and with the estimation by MAEDA et al. (1979) from the observed $S q$ field. This supports the ability of the MU radar to measure the drift velocity or electric field in the ionosphere, and if observations were made simultaneously with other IS radars, it is expected that the UT dependence of the electrostatic potential in the ionosphere would be revealed more clearly.

\section{Conclusion}

We have measured the ion drift and electron density profile in the $F$ region by using MU radar during two periods, September 17-18 and October 7-8, 1986, and compared the estimated and observed geomagnetic field variations. The following are the major points:

1) In the period from $23 \mathrm{~h} \mathrm{LT}$ to $24 \mathrm{~h} \mathrm{LT}$ on September 17, a clear difference was found between the electron density profiles observed by the eastward and 

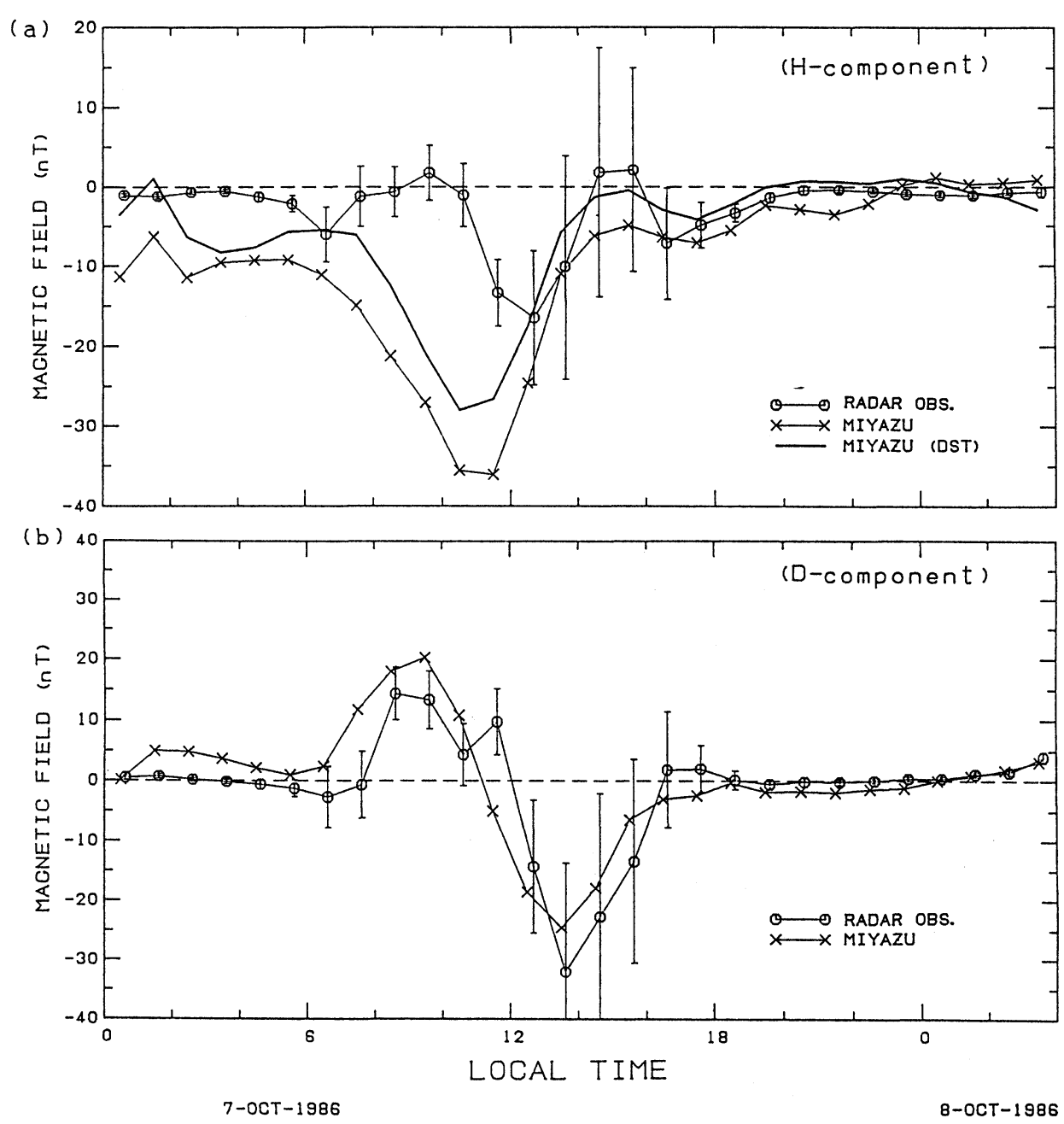

Fig. 9. Same as in Fig. 4, but from $00 \mathrm{~h} \mathrm{LT}$ on October 7 to $03 \mathrm{~h} \mathrm{LT}$ on October 8, 1986.

westward beams, which may be caused by a wave propagated from east to west.

2) A clear negative correlation between the perpendicular northward $\left(V_{\perp}\right)$ and parallel $\left(V_{l /}\right)$ components of the velocity was often found. This is caused by the $F$ region dynamo action.

3) The daily variation pattern of $V_{\perp}$ was similar to that observed at Arecibo, especially in the daytime, but that of the eastward drift was different.

4) Geomagnetic field variations estimated from the drift velocity are partly in accordance with the observation. The discordance between them was concluded to be caused by ionospheric winds, which contribute to the generation of the geomagnetic $S q$ field through the induced electric field. 


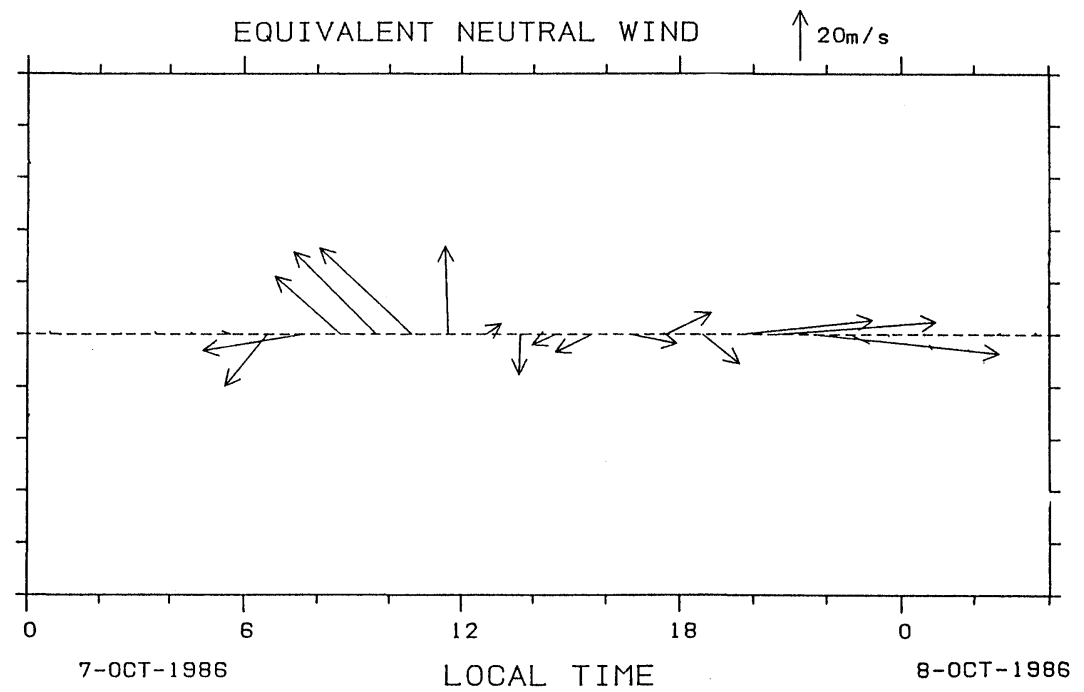

Fig. 10. Calculated neutral wind system from the difference between the calculated and observed geomagnetic fields at Miyazu from $00 \mathrm{~h} \mathrm{LT}$ on October 7 to $03 \mathrm{~h} \mathrm{LT}$ on October 8, 1986.

The MU radar belongs to and is operated by the Radio Atmospheric Science Center of Kyoto University. The geomagnetic data used in the present study were obtained from the World Data Center C2 for Geomagnetism, and data processing was partly made by using facilities at the Data Processing Center, Kyoto University. We thank one of the referees for many comments which were very helpful in improving this paper.

\section{REFERENCES}

Behnke, R. A. and R. M. HARPer, Vector measurements of $F$-region ion transport at Arecibo, $J$. Geophys. Res., 78, 8222-8234, 1973.

Fukao, S., T. Sato, I. Kimura, and R. M. Harper, Seasonal mean structure of the night-time $F 2$ region over Arecibo, J. Atmos. Terr. Phys., 41, 1205-1211, 1979.

Fukao, S., T. Sato, T. Tsuda, S. Kato, K. Wakasugi, and T. Makihira, The MU radar with an active phased array system, 1. Antenna and power amplifiers, Radio Sci., 20, 1155-1168, 1985a.

Fukao, S., T. Sato, T. Tsuda, S. Kato, K. Wakasugi, and T. Makihira, The MU radar with an active phased array system, 2. In-house equipment, Radio Sci., 20, 1169-1176, $1985 \mathrm{~b}$.

Fukushima, N., Three-dimensional electric current and toroidal magnetic field in the ionosphere, Rept. Ionosphere Space Res. Japan, 22, 173-195, 1968.

Fukushima, N., Electric potential difference between conjugate points in middle latitudes caused by asymmetric dynamo in the ionosphere, J. Geomag. Geoelectr., 31, 401-409, 1979.

Gauguly, S., R. A. Behnke, and B. A. Emery, Average electric field behavior in the ionosphere above Arecibo, J. Geophys. Res., 92, 1199-1210, 1987.

HARPER, R. M., A comparison of ionospheric currents, magnetic variations and electric fields at Arecibo, J. Geophys. Res., 82, 3233-3242, 1977.

IRI 79, International Reference Ionosphere, Report UAG-82, World Data Center for Solar Terrestrial Physics, NOAA, Boulder Colorado, USA, 1981.

Maeda, H., T. Araki, A. Suzuki, and M. TakedA, Electric fields and neutral winds in the ionospheric 
dynamo region, World Data Center C2 for Geomagnetism Data Book No. 2, Data Analysis Center for Geomagnetism and Spacemagnetism, Faculty of Science, Kyoto University, Japan, 1979.

Mazaudier, C., Electric currents above St. Santin, 1. Data, J. Geophys. Res., 87, 2459-2464, 1982.

Oliver, W. L., S. Fukao, T. Sato, T. Tsuda, S. Kato, I. Kimura, A. Ito, T. Saryo, and T. Araki, Ionospheric incoherent scatter measurements with the MU radar: Observations of $F$-region electrodynamics, J. Geomag. Geoelectr., 40, 963-985, 1988.

Richmond, A. D., M. Blanc, B. A. Emery, R. H. Wand, B. G. Fejer, R. F. Woodman, S. Gauguly, P. Amayenc, R. A. Behnke, C. Calderon, and J. V. Evans, An empirical model of quiet-day ionospheric electric fields at middle and low latitudes, J. Geophys. Res., 85, 4658-4664, 1980.

SAto, T., A. ITo, and W. L. Oliver, Ionospheric incoherent scatter measurements with the MU radar: Techniques and capability, Radio Sci., 24, 85-98, 1989.

TAKedA, M., Day-to-day variation of equivalent $S q$ current system during March 11-26, 1970, J. Geomag. Geoelectr., 36, 215-228, 1984.

TAKEDA, M. and Y. YAMADA, Simulation of ionospheric electric fields and geomagnetic field variation by the ionospheric dynamo for different solar activity, Ann. Geophysicae, 5A, 429-434, 1987. 